\title{
Night-time consumption of protein or carbohydrate results in increased morning resting energy expenditure in active college-aged men
}

\author{
Takudzwa A. Madzima, Lynn B. Panton, Sarah K. Fretti, Amber W. Kinsey and Michael J. Ormsbee* \\ Department of Nutrition, Food and Exercise Sciences, Institute of Sports Science and Medicine, The Florida State University, \\ 120 Convocation Way, 430 Sandels Building, Tallahassee, FL 32311, USA \\ (Submitted 14 December 2012 - Final revision received 15 May 2013 - Accepted 16 May 2013 - First published online 17 June 2013)
}

\section{Abstract}

The purpose of the present study was to investigate whether whey protein (WP), casein protein (CP), carbohydrate (CHO) or a non-energy-containing placebo (PLA) consumed before sleep alters morning appetite and resting energy expenditure (REE) in active men. A total of eleven men (age: 23.6 (sem 1.0) years; body fat: 16.3 (sem 2.5) \%) participated in this randomised, double-blind, crossover study. A single dose of WP (30 g), CP (30 g), CHO (33 g) or PLA was consumed 30 min before sleep, and each trial was separated by $48-72 \mathrm{~h}$. The next morning (05.00-08.00 hours), measurements of satiety, hunger and desire to eat and REE were taken. After a $30 \mathrm{~min}$ equilibration period, REE in the supine position was measured for $60 \mathrm{~min}$. An analysis of 10 min mean intervals over the final $50 \mathrm{~min}$ of the measurement period was conducted. Statistical analyses were conducted using repeated-measures ANOVA for metabolic variables, and a one-way ANOVA was used for measuring changes in appetite markers. Group differences were examined by Tukey's post hoc analysis. There were no significant differences in appetite measures among the groups. There was a main group effect for REE. The predicted REE was significantly greater after consumption of the WP (8151 (sEM 67) kJ/d), CP (8126 (sEM 67) kJ/d) and CHO $(7988($ sem 67$) \mathrm{kJ} / \mathrm{d})$ than after that of the PLA $(7716$ (sEm 67) kJ/d, $P<0 \cdot 0001)$. There were no significant differences between the WP and CP groups in any metabolic measurements. Night-time consumption of WP, CP or CHO, in the hours close to sleep, elicits favourable effects on the next-morning metabolism when compared with that of a PLA in active young men.

Key words: RMR: Night-time eating: Whey protein: Casein protein

It is well known that proteins elicit greater thermic effects, increase resting energy expenditure $(\mathrm{REE})^{(1-3)}$ and satiety ${ }^{(4,5)}$ and decrease respiratory exchange ratios in the immediate postprandial period ${ }^{(1,6,7)}$ when compared with carbohydrates (CHO) and fats. Furthermore, the addition of a protein supplement to a normal diet promotes weight loss and maintenance, mainly as a result of increases in satiety ${ }^{(8,9)}$ and energy expenditure ${ }^{(1,10,11)}$.

The positive physiological effects of protein consumption have primarily been observed in studies investigating the postprandial effects of mixed meals consumed in the morning and afternoon $^{(11-14)}$ or after consumption of single macronutrients in the hours close to exercise ${ }^{(15-17)}$. However, less is known about the effects of different macronutrients consumed in the late evening within 30 to $60 \mathrm{~min}$ of sleep on the desire to eat and REE the following morning.

Night-time eating is a largely unexplored component of nutrient timing studies and could be a key factor that plays an instrumental role in the modulation of the effects of different macronutrients on body composition, metabolism and satiety. Until recently, the majority of the information regarding what individuals should be consuming at night has been anecdotal and based on the idea that late-evening ingestion of food will increase the likelihood of weight gain ${ }^{(18)}$. The potential for weight gain with late-evening food consumption is plausible given that both metabolic rate ${ }^{(19)}$ and satiety ${ }^{(18)}$ are reduced during this time, which may favour a positive energy balance. For this reason, it has been recommended that individuals concerned with weight regulation avoid consuming energy-containing products in the hours close to sleep due to the potential body composition implications associated with increased food intake and attenuated physiological functioning. However, this is not the case for physically active individuals who would probably benefit from a constant flow of nutrients that may be necessary for optimal recovery both post-exercise and during the overnight period $^{(17,20)}$.

Interestingly, the milk proteins, whey protein (WP) and casein protein $(\mathrm{CP})$, are digested and absorbed at different rates $^{(21)}$. $\mathrm{CP}$ has been described as a 'slow protein' due to the slower digestion and absorptive rates observed compared

Abbreviations: CHO, carbohydrate; CP, casein protein; PLA, non-energy-containing placebo; REE, resting energy expenditure; WP, whey protein.

*Corresponding author: M. J. Ormsbee, fax +1 850645 5000, email mormsbee@fsu.edu 
with those of WP, and therefore $\mathrm{CP}$ has popularly been recommended as a night-time protein ${ }^{(21)}$. Furthermore, in some $^{(6,7)}$, but not all ${ }^{(14)}$, studies, $\mathrm{CP}$ has been shown to increase satiety and reduce appetite to a greater extent when compared with WP. Recently, Res et al. ${ }^{(17)}$ have reported that oral $\mathrm{CP}$ consumption before sleep results in elevated muscle protein synthesis throughout the sleeping hours compared with non-energy-containing placebo (PLA) consumption in healthy young men after a resistance exercise bout. Another study carried out in this laboratory has demonstrated that $\mathrm{CP}$ administered via nasogastric tubing during sleep increased overnight muscle protein synthesis in elderly men ${ }^{(22)}$. These data highlight the potential benefits of providing a constant flow of nutrients through night-time protein intake. It is possible that night-time protein intake may be a new window of opportunity for physiological benefits and, in the long term, optimal performance, but no studies have compared the effects of different proteins consumed before bed.

Therefore, the present study investigated the extent to which a single serving of WP, CP, CHO or a PLA before sleep affects satiety and metabolism, independent of exercise, in healthy, physically active young men. We hypothesised that consumption of protein at night before sleep would have a positive impact on next-morning metabolism and appetite to a greater extent than that of $\mathrm{CHO}$ or a PLA beverage.

\section{Methods}

\section{Participants}

In the present study, eleven physically active $(\geq 4 \mathrm{~d} /$ week and $50 \mathrm{~min} / \mathrm{d}$ of self-reported moderate-to-vigorous physical activity for $>12$ months) college-aged men (age: $23 \cdot 6$ (SEm 1.0) years; height: $183 \cdot 1$ (SEM 2.2) cm; weight: $86 \cdot 2$ (SEM 3.5) kg; BMI: $25.8(\operatorname{sem} 0.8) \mathrm{kg} / \mathrm{m}^{2}$; and body fat: 16.3 (SEm 2.5)\%) participated. Participants were excluded if they had uncontrolled hypertension (blood pressure $>160 / 100 \mathrm{mmHg}$ ), were taking blood pressure or cholesterol medications, or had been diagnosed with CVD, stroke, diabetes, or thyroid or kidney dysfunction or had milk allergies. Additionally, all smokers were excluded. The participants were asked to refrain from taking any nutritional supplements (except for a multivitamin) for 2 weeks before their first laboratory visit and throughout the duration of the study. In addition, the participants were asked to maintain their usual exercise regimen for the duration of the study. The present study was conducted according to the guidelines laid down in the Declaration of Helsinki, and all procedures involving human participants were approved by the Florida State University Institutional Review Board. Written informed consent was obtained before participation in the study.

\section{Study design}

The study had a randomised, double-blind, cross-over design. Before the start of the study, the participants reported to the laboratory for baseline measurements of height (Seca Corporation), weight (Detecto ${ }^{\circledR}$; DETECTO Scale Company), waist and hip circumferences (Creative Health Products, Inc.), and body composition via air-displacement plethysmography (BOD POD ${ }^{\circledR}$; COSMED). WP and CP are the commonly consumed supplements by physically active individuals and have been associated with improvements in many physiological outcomes ${ }^{(17,22-24)}$. Therefore, these proteins were administered in the present study. The following four supplements were randomly consumed with each trial being separated by $48-72 \mathrm{~h}$ : (1) WP $(38 \mathrm{~g}, 628 \mathrm{~kJ}$ (150 kcal), $30 \mathrm{~g}$ protein, $3 \mathrm{~g} \mathrm{CHO}$ and $2 \mathrm{~g}$ fat); (2) CP (38g, $586 \mathrm{~kJ}$ (140 kcal), $30 \mathrm{~g}$ protein, $3 \mathrm{~g} \mathrm{CHO}$ and $1 \mathrm{~g} \mathrm{fat})$; (3) $\mathrm{CHO}$ (maltodextrin; $38 \mathrm{~g}, 628 \mathrm{~kJ}(150 \mathrm{kcal}), 0 \mathrm{~g}$ protein, $33 \mathrm{~g} \mathrm{CHO}$ and $2 \mathrm{~g}$ fat); (4) PLA $\left(2.9 \mathrm{~g}, 0 \mathrm{~kJ}\right.$ (0 kcal); Propel Zero ${ }^{\mathrm{TM}}$; PepsiCo Inc.). Powdered WP, CP and $\mathrm{CHO}$ were labelled A, $\mathrm{B}$ and $\mathrm{C}$ and packaged by an external investigator who was not otherwise involved in the study. All powders were flavoured identically (vanilla chai) and had an identical texture to ensure that the participants were truly blinded to each experimental trial. The non-energy-containing PLA (Propel Zero $^{\mathrm{TM}}$ ) was also in a powdered form and was labelled as supplement D. The flavour and consistency of the PLA were different from those of the WP, CP and CHO powders. Therefore, the PLA was single blinded and not double blinded to the participants. The administered dose of $30 \mathrm{~g}$ was chosen because it has previously been shown to be ideal for healthy, physically active men ${ }^{(25,26)}$, and the $627 \mathrm{~kJ}$ (150 kcal) serving was chosen in an attempt to offer a reasonable energetic load that mimics many manufactured protein beverages. All supplements were consumed at home with $12 \mathrm{oz}$ of water as the last food or energy-containing beverage of the day, taken at least $1 \mathrm{~h}$ following consumption of the participant's last evening meal and within $30 \mathrm{~min}$ of going to sleep. The morning following the evening consumption (05.00-08.00 hours), the participants reported to the laboratory for the measurement of satiety and metabolism.

On two consecutive days before each experimental trial, all the participants completed a dietary log and were asked to replicate this eating pattern before each visit. Compliance was verified by the analysis of food records by the same research technician (United States Department of Agriculture, www.choosemyplate.gov). Furthermore, the participants were instructed to refrain from consuming caffeine or alcohol and undertaking any planned physical activity $24 \mathrm{~h}$ before each visit.

\section{Hunger, satiety and desire to eat assessment}

Upon arrival to the laboratory on each test morning, the participants completed a visual analogue scale ${ }^{(27)}$ to subjectively assess hunger, satiety and desire to eat. The visual analogue scale is a $100 \mathrm{~mm}$ horizontal scale with opposing extremes ('not at all' to 'extremely') of each appetite sensation (hunger, satiety and desire to eat) anchored at each end of the $100 \mathrm{~mm}$ line. The participants indicated their subjective feelings by placing a vertical line along the $100 \mathrm{~mm}$ scale, and each rating was converted to a score in mm using a standard ruler. Higher scores indicated greater feelings of each sensation. 
Table 1. Visual analogue scale of hunger, satiety and desire to eat $(n 11)$

(Mean values with their standard errors)

\begin{tabular}{|c|c|c|c|c|c|c|c|c|}
\hline & \multicolumn{2}{|c|}{$\mathrm{CHO}$} & \multicolumn{2}{|c|}{ WP } & \multicolumn{2}{|c|}{$\mathrm{CP}$} & \multicolumn{2}{|c|}{ PLA } \\
\hline & Mean & SEM & Mean & SEM & Mean & SEM & Mean & SEM \\
\hline Hunger (mm) & $44 \cdot 4$ & $6 \cdot 74$ & $39 \cdot 4$ & $6 \cdot 74$ & $36 \cdot 6$ & $6 \cdot 74$ & $44 \cdot 1$ & $6 \cdot 74$ \\
\hline Satiety (mm) & $36 \cdot 1$ & $5 \cdot 42$ & $40 \cdot 6$ & $5 \cdot 42$ & $45 \cdot 4$ & $5 \cdot 42$ & 33.9 & $5 \cdot 42$ \\
\hline Desire to eat $(\mathrm{mm})$ & $43 \cdot 2$ & $7 \cdot 20$ & $43 \cdot 4$ & $7 \cdot 20$ & $40 \cdot 6$ & $7 \cdot 20$ & $53 \cdot 3$ & $7 \cdot 20$ \\
\hline
\end{tabular}

$\mathrm{CHO}$, carbohydrate; WP, whey protein; $\mathrm{CP}$, casein protein; PLA, placebo.

\section{Resting energy expenditure}

Following the visual analogue scale measurements, the participants were asked to lie supine on a bed in a dark, quiet and climate-controlled room $\left(20-22^{\circ} \mathrm{C}\right)$ for $30 \mathrm{~min}$ in an effort to have them feel completely rested. Gas exchange was then measured continuously for $60 \mathrm{~min}$ to assess $\mathrm{VO}_{2}$ $(\mathrm{ml} / \mathrm{kg}$ per $\mathrm{min}), \mathrm{REE}(\mathrm{kcal} / \mathrm{d})$ and respiratory quotient via indirect calorimetry using a ventilated hood (TrueOne 2400 metabolic cart; ParvoMedics). The last $50 \mathrm{~min}$ of the data collection period were used for analysis and compared across five $10 \mathrm{~min}$ segments over the last $50 \mathrm{~min}$ period. The test-retest intra-class $\mathrm{CV}$ for the measurement of REE in our laboratory is $1.7 \%$.

\section{Anthropometrics and body composition}

Upon completion of the metabolic measurements, the participants had their height and weight measured without shoes while wearing only spandex shorts to the nearest $0 \cdot 1 \mathrm{~cm}$ and $0 \cdot 1 \mathrm{~kg}$, respectively, via a wall-mounted stadiometer (Seca Corporation) and a digital scale (Detecto ${ }^{\circledR}$ ). Waist and hip circumferences were taken a minimum of two times using a Gulick fibreglass measuring tape with a tension handle (Creative Health Products, Inc.). Additional measurements were taken if duplicate readings were in excess of $5 \mathrm{~mm}$ of each other, until the discrepancy between the two readings was equal to or less than $5 \mathrm{~mm}$. Body composition (\% body fat, lean and fat mass) was measured with the participants wearing spandex shorts and a lycra cap over their hair via air-displacement plethysmography (BOD POD $^{\circledR} ;$ COSMED) ${ }^{(28)}$.

\section{Statistical analyses}

Statistical analyses were conducted using JMP Pro 10 (SAS). A $4 \times 5$ (group $\times$ time) repeated-measures ANOVA was conducted to measure differences during each of the five $10 \mathrm{~min}$ segments of the final $50 \mathrm{~min}$ period of indirect calorimetry. A one-way ANOVA was conducted for the measurement of hunger, satiety and desire to eat for each trial. Tukey's post hoc analysis was used where appropriate to examine group differences. A Shapiro test was used to ensure normality for body fat percentage and BMI. Significance was set at $P<0.05$, and data are reported as mean with their standard errors, unless otherwise noted.

\section{Results}

There were no differences in total energy, protein, $\mathrm{CHO}$ or fat consumed before any of the four experimental trials. The analysis of the $2 \mathrm{~d}$ dietary logs indicated that an average of 9223 (SEM 3169) kJ/d (2204 (SEM 757) kcal/d) was consumed (19.9) (SEM 6.6)\% protein, 48.4 (SEM 9.5) \% $\mathrm{CHO}$ and 30.8 (sEM 8.2 )\% fat).

Subjective assessments of hunger, satiety and desire to eat are presented in Table 1 . No significant differences were observed for hunger, satiety or desire to eat among the WP, $\mathrm{CP}, \mathrm{CHO}$ and PLA groups. However, although not statistically significant, satiety (feeling of fullness) after consumption of both WP $(40.6(\operatorname{SEM} 5.4) \mathrm{mm})$ and CP $(45.4(\operatorname{SEM~} 0.4) \mathrm{mm})$
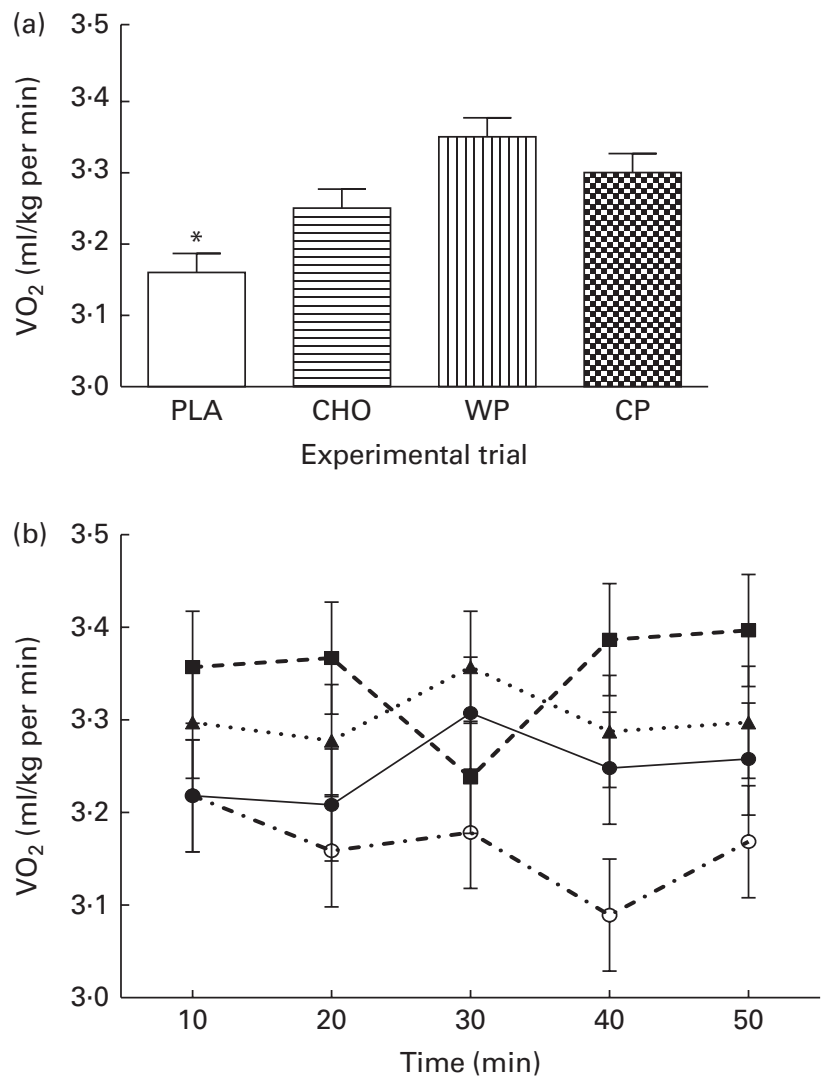

Fig. 1. (a) $\mathrm{VO}_{2}\left(\mathrm{ml} / \mathrm{kg}\right.$ per min) and (b) $10 \mathrm{~min}$ intervals of $\mathrm{VO}_{2}(\mathrm{ml} / \mathrm{kg}$ per $\mathrm{min}$ ) for $50 \mathrm{~min}$ the morning after night-time consumption of a single serving of whey protein (WP), casein protein $(\mathrm{CP})$, maltodextrin $(\mathrm{CHO})$ and a non-energetic placebo (PLA). Values are means, with their standard errors represented by vertical bars. ${ }^{*}$ Mean value was significantly different from that of WP and CP $(P<0 \cdot 05)$. (b) -๑-, PLA; - - $\mathrm{CHO} ;--$, WP; $\ldots$..., CP. 

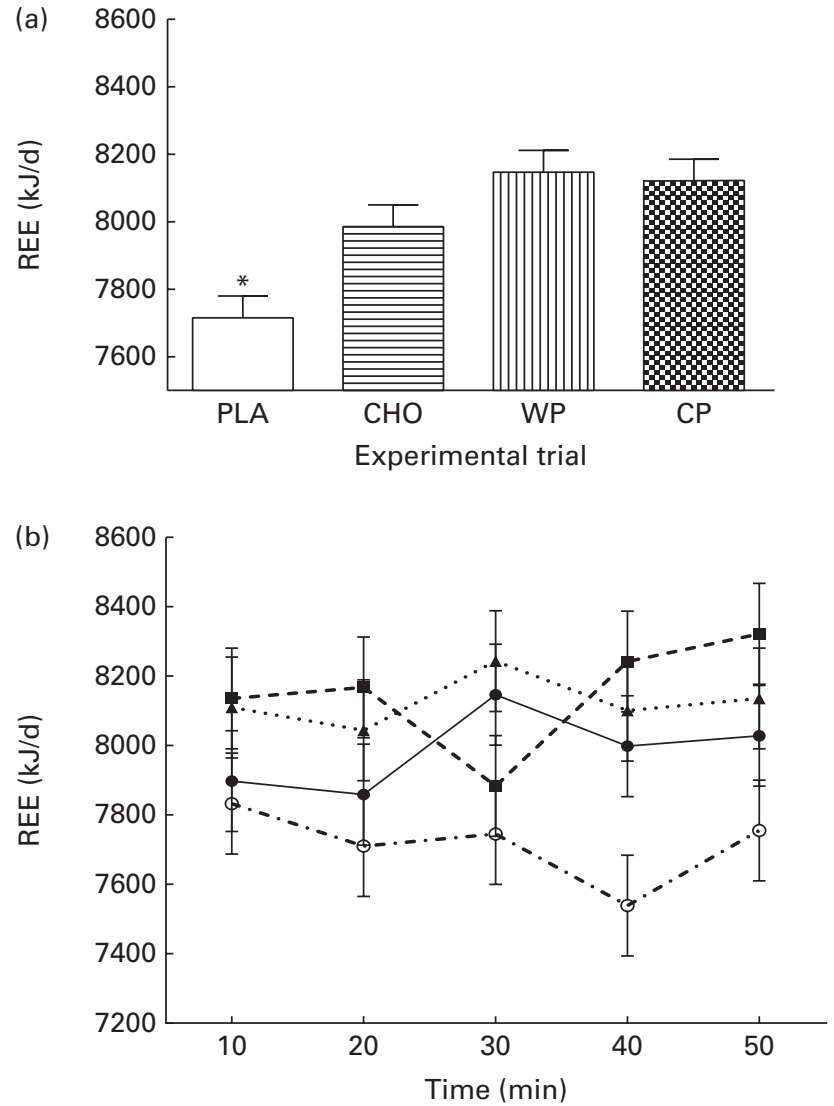

Fig. 2. (a) Predicted resting energy expenditure (REE, $\mathrm{kJ} / \mathrm{d}$ ) and (b) $10 \mathrm{~min}$ intervals of predicted REE $(\mathrm{kJ} / \mathrm{d})$ for $50 \mathrm{~min}$ the morning after night-time consumption of a single serving of whey protein (WP), casein protein (CP), maltodextrin ( $\mathrm{CHO}$ ) and a non-energetic placebo (PLA). Values are means, with their standard errors represented by vertical bars. ${ }^{*}$ Mean value was significantly different from that of WP, $\mathrm{CP}$ and $\mathrm{CHO}(P<0.05)$. (b) - $\odot--$, PLA; --, $\mathrm{CHO} ;-$ - - - WP; ....., CP.

was greater than that after consumption of $\mathrm{CHO}(36 \cdot 1$ (SEM 5.4) mm) and PLA (33.9 (SEM 5.4) mm). Metabolic assessment of $\mathrm{VO}_{2}(\mathrm{ml} / \mathrm{kg}$ per min) was done continuously for $60 \mathrm{~min}$, and $10 \mathrm{~min}$ mean intervals from the final $50 \mathrm{~min}$ period were analysed (Fig. 1). There were no group $\times$ time interactions or time effects; however, there were group differences. Mean $\mathrm{VO}_{2}(\mathrm{ml} / \mathrm{kg}$ per min) for the WP (3.35 (SEM 0.03$) \mathrm{ml} / \mathrm{kg}$ per $\mathrm{min}$ ) and CP (3.30 (sEm 0.03) $\mathrm{ml} / \mathrm{kg}$ per min) groups were significantly $(P<0.0001)$ greater than those for the PLA group $(3.16$ (SEM 0.03$) \mathrm{ml} / \mathrm{kg}$ per min) but not for the CHO group (3.25 (sem 0.03$) \mathrm{ml} / \mathrm{kg}$ per $\mathrm{min}$ ) (Fig. 1(a)). Additionally, there were no significant differences between the WP and CP groups or between the CHO and PLA groups for $\mathrm{VO}_{2}$ (Fig. 1). Interestingly, although not statistically significant, the PLA group had a lower $\mathrm{VO}_{2}$ at 20, 30, 40 and 50 min than the WP, CP and CHO groups (Fig. 1(b)).

The predicted REE $(\mathrm{kJ} / \mathrm{d} ; \mathrm{kcal} / \mathrm{d})$ measurements during $10 \mathrm{~min}$ mean intervals from the final $50 \mathrm{~min}$ of the data collection period are presented in Fig. 2. There were no group $\times$ time interactions or time effects; however, there were group differences. The predicted REE was significantly greater after consumption of the WP (8151 (sEm 65) kJ/d; 1947
(SEM 16) kcal/d), CP (8126 (sEM 65) kJ/d; 1941 (sEm 16) kcal/d) and $\mathrm{CHO}(7988($ SEM 65$) \mathrm{kJ} / \mathrm{d} ; 1908$ (SEM 16) kcal/d) than after that of the PLA $(7716$ (SEM 65) kJ/d; 1843 (SEM 16) kcal/d; $P<0 \cdot 0001$ ). There were no significant differences between the WP, CP and $\mathrm{CHO}$ groups. Similar to that observed for $\mathrm{VO}_{2}$, there were no differences at baseline (minute 10) and, although not significant, the PLA group had the lowest REE at all the other time points. Respiratory quotient $\left(\mathrm{VCO}_{2} / \mathrm{VO}_{2}\right)$ was significantly lower after consumption of the PLA (0.76 (SEM 0.003)) than after that of the WP (0.77 (SEM 0.003)) and $\mathrm{CHO}(0.77$ (SEM 0.003); $P<0.0001)$, but not after that of the CP (0.76 (SEM 0.003)) (Fig. 3).

\section{Discussion}

The ability of proteins to increase thermogenesis, and therefore REE, to a greater extent than $\mathrm{CHO}$ has been well documented in acute studies ${ }^{(1,6,29-31)}$. The positive physiological effects of proteins have been observed after daytime consumption $^{(1,7,32)}$ or in the hours close to resistance exercise $^{(15,17,33)}$. However, to our knowledge, no studies have investigated satiety or REE changes after protein consumption before sleep, and none has compared then after WP, CP and $\mathrm{CHO}$ consumption during this time frame.

The main findings of the present study are that there were no differences between the effects of protein and $\mathrm{CHO}$ on morning REE or subjective feelings of satiety when consumed before sleep in healthy, physically active young men. Furthermore, there were no significant differences between the effects of WP and CP consumption on morning REE. Interestingly, the WP, CP and CHO elicited a significantly greater effect on morning REE than the PLA. Our data suggest that, regardless of the macronutrient type, consuming $586-628 \mathrm{~kJ}$ $(140-150 \mathrm{kcal})$ of a supplement in liquid form before bed has a superior effect on morning $\mathrm{VO}_{2}$ and REE than going to bed on an empty stomach. This finding has relevance to healthy, physically active individuals and may extend to populations that are trying to lose and/or maintain body weight.

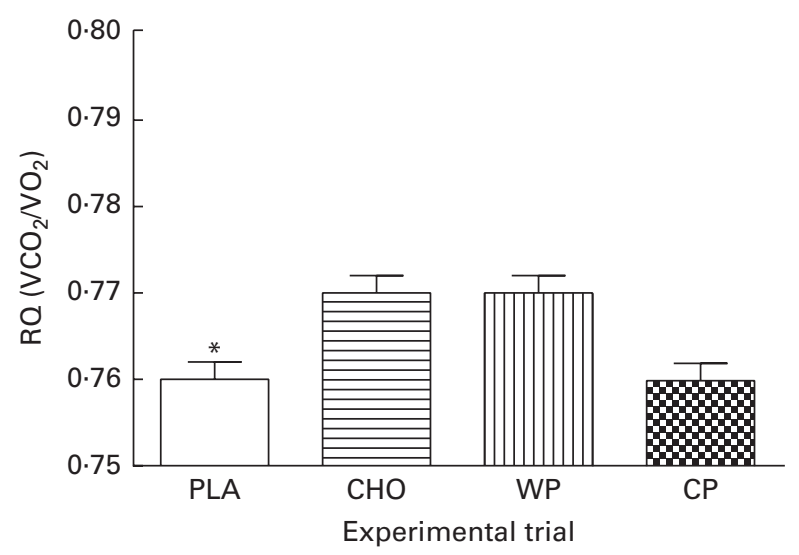

Fig. 3. Respiratory quotient $(R Q)$ the morning after night-time consumption of a single serving of whey protein (WP), casein protein (CP), maltodextrin $(\mathrm{CHO})$ and a non-energetic placebo (PLA). Values are means, with their standard errors represented by vertical bars. * Mean value was significantly different from that of WP and $\mathrm{CHO}(P<0.05)$, but not CP. 
Traditional practice has been to limit energy intake in the late evening in an attempt to prevent storing energy consumed as fat because metabolism is thought to slow during sleep. Although metabolism has been shown to slow at night ${ }^{(19)}$, no scientific evidence has shown this to be true after consuming food before sleep. Our findings suggest that energy intake of $586-628 \mathrm{~kJ}(140-150 \mathrm{kcal})$ before sleep actually increases $\mathrm{VO}_{2}$ and predicted REE.

It is well documented that proteins have a superior thermogenic and satiating effect than $\mathrm{CHO}$ and fats, and still less is known whether differences exist between protein types. In agreement with the present results, Lorenzen et $a l .{ }^{(32)}$ reported no differences in postprandial REE between three $1465 \mathrm{~kJ}$ $(350 \mathrm{kcal})$ mixed breakfast meals, each containing $36 \mathrm{~g} \mathrm{WP}$, $34 \mathrm{~g} \mathrm{CP}$ or milk ( $28 \mathrm{~g}$ casein and $7 \mathrm{~g}$ whey). In contrast, Acheson et ll $^{(1)}$ found the thermic effect of $1921 \mathrm{~kJ}$ ( $459 \mathrm{kcal}$ ) of a WP mixed meal to be greater than that of isoenergetic casein and soya protein meals and found all protein groups to have a greater thermogenic effect than $1921 \mathrm{~kJ}$ (459 kcal) of CHO in twenty-three healthy lean men and women. Moreover, $30 \mathrm{~g}$ of WP ( $502 \mathrm{~kJ}$ or $120 \mathrm{kcal}$ ) did not affect REE in middle-aged women and decreased fat oxidation compared with a non-energetic placebo when consumed immediately postexercise $^{(33)}$. These conflicting findings demonstrate the need for more research investigating the effect of protein choice, particularly at night, on metabolism. Furthermore, the energy consumed in the experimental trials of the aforementioned studies varied and were different from the $586-628 \mathrm{~kJ}$ $(140-150 \mathrm{kcal})$ used in the present study. Therefore, future research should focus on determining the optimum energetic load needed to elicit favourable changes in REE. Nevertheless, consumption of $40 \mathrm{~g}$ of $\mathrm{CP}$ before sleep has been shown to stimulate muscle protein synthesis overnight in both young $^{(17)}$ and elderly ${ }^{(22)}$ men, and it is likely that, in the long term, this increase in muscle protein synthesis will result in an increase in REE. The energy load reported by these studies is at least $669 \mathrm{~kJ}(160 \mathrm{kcal})$, which is very similar to the energy load observed in the present study. However, these authors did not specify whether any additional energy was provided by their casein supplement, so a true comparison is not possible.

When compared with $\mathrm{CHO}$, several studies have observed an increased satiating effect of protein-rich breakfast and lunch in the postprandial period ${ }^{(3,8,34,35)}$. Although not significant, the present results indicate that a single serving of WP or $\mathrm{CP}$ before sleep has a greater satiating effect than that of $\mathrm{CHO}$. The present results are in agreement with those reported by Bowen et $a l{ }^{(35)}$, who found proteins to improve satiety more than $\mathrm{CHO}$. Although the improved satiating effect of proteins compared with that of $\mathrm{CHO}$ has been demonstrated, the debate regarding which type of protein best modulates satiety is ongoing. The satiating effects of certain proteins may be dose dependent, as shown by Smeets et al. ${ }^{(36)}$, who reported energy expenditure and satiety to be acutely improved after consumption of a single high-protein lunch ( $25 \%$ energy from protein) than after that of an adequate protein meal (10\% energy from protein) in thirty healthy men and women $(P<0.02)$ with each meal comprising $35 \%$ of each participant's daily energy requirements. More recently, Veldhorst et $a l^{(12-14)}$ have examined the effects of a mixed breakfast meal containing whey, casein or soya protein at fixed doses (20\% of daily energy requirement) on satiety for $4 \mathrm{~h}$ after ingestion in thirty healthy men and women. A breakfast containing $10 \%$ energy from whey was more satiating than that containing $10 \%$ casein at all time points and $10 \%$ soya $20 \mathrm{~min}$ after breakfast $(P<0.05)^{(14)}$. There were no differences between proteins at $25 \%$ energy intake, an intake considered higher than normal, suggesting that after a certain amino acid threshold, whey, casein and soya as part of a breakfast have similar satiating effects ${ }^{(14)}$. The dose-dependent effects of different proteins on subjective assessments of satiety may explain the similarities between the WP and CP treatments in the present study, as both used $30 \mathrm{~g}$ of the respective proteins.

There are a number of potential reasons for the discrepancy between the findings of the aforementioned studies and our findings. To date, the effects on satiety have been reported after daytime protein consumption and typically as part of a mixed meal. The present study, however, investigated the effects of a single serving of different proteins consumed before sleep on morning (8-10 h later) satiety. Furthermore, we measured subjective feelings of hunger, satiety and desire to eat several hours after consumption of the WP, CP, $\mathrm{CHO}$ or PLA. Thus, the elapsed time may have contributed to the lack of significant differences in the measures of satiety. In addition, it has also been reported that individuals with habitually high protein intakes have a diminished satiating response to a single protein meal ${ }^{(37)}$. As our participants were active college-aged men, their diets may have contained higher-than-standard protein amounts $(1.3 \mathrm{~g} / \mathrm{kg}$ per $\mathrm{d} ; 19 \cdot 8$ (SEM 5.3)\% protein), which may explain the lack of a significant effect on appetite in the present study. Furthermore, Groen et $a l^{(22)}$ reported that overnight administration of $40 \mathrm{~g}$ of casein elicited normal dietary protein digestion and absorption kinetics. In addition, during the $5 \mathrm{~h}$ overnight postprandial period, the authors observed that the amount of available circulating protein from the casein bolus was similar to that observed after whey consumption during the day. In addition, other authors have reported similar amino acid availability $5 \mathrm{~h}$ following morning whey or casein consumption $^{(38-40)}$. These findings suggest similar protein digestion and absorption kinetics overnight between the WP and CP, thereby possibly explaining our lack of significant differences between protein types.

Further inconsistency exists in the literature with regard to macronutrient type and fat oxidation. Similar to our findings, Benton et al. ${ }^{(33)}$ reported fat oxidation (respiratory exchange ratios) to be significantly diminished after $30 \mathrm{~g}$ post-exercise whey supplementation $(502 \mathrm{~kJ}$ or $120 \mathrm{kcal}) 120 \mathrm{~min}$ after consumption compared with PLA supplementation $(P=0.02)$. We found fat oxidation, as assessed by respiratory exchange ratios, to be significantly lower after consumption of the WP and $\mathrm{CHO}(P=0.0003)$ but not after that of the CP. WP has been shown to have significantly $(P<0.05)$ lower $^{(1)}$ and higher ${ }^{(32)}$ respiratory exchange ratio values than $\mathrm{CHO}$ and $\mathrm{CP}$, respectively. Interestingly, in the present study, in addition 
to having a significantly greater $\mathrm{REE}$ and $\mathrm{VO}_{2}$ response, the $\mathrm{CP}$ group had a response similar to that of the PLA group for fat oxidation. While we were unable to collect blood in the present study, Pennings et al. ${ }^{(23)}$ reported that casein ingestion results in a significantly lower insulin response when compared with WP or $\mathrm{CHO}$ ingestion. Insulin can dramatically lower fat oxidation, and this could explain the small differences in fat oxidation that we observed. The slow-digesting nature of CP may have resulted in a blunted insulin response, thereby resulting in greater fat utilisation when compared with the faster-digesting WP and $\mathrm{CHO}$. Therefore, it is plausible that in addition to improving REE, CP may be an ideal macronutrient for utilising fat as a fuel source in the late evening.

A few limitations exist and need to be addressed. Differences in taste, serving size and texture of the PLA may have confounded the subjective feelings of hunger, satiety and desire to eat. However, the decision to add a non-energycontaining PLA was necessary for the measurements of $\mathrm{VO}_{2}$ and REE to identify differences between energy intake and not consuming energy before sleep. Likewise, although we randomised the order of each experimental trial and required a $48-72 \mathrm{~h}$ washout period between laboratory visits, it is possible that the order of treatments may have confounded our findings. Furthermore, although purely speculation, the physical differences between the PLA and WP/CP/CHO supplements would probably have little impact on metabolic measurements via indirect calorimetry. In addition, the question remains as to whether the energy load of the ingested supplements was offset by the increase in REE over the sleeping hours or the next day. Therefore, future research should investigate metabolism through the overnight period and for a duration longer than $60 \mathrm{~min}$ the following morning to fully understand any weight management implications of the present findings. As very limited research exists on whether it is detrimental to consume energy-containing products before sleep, the present findings begin to identify what active people should consume in the late evening before sleep.

\section{Conclusions}

The majority of studies have compared the effects of different proteins, macronutrients and energy loads when consumed in the morning. The present study is the first to investigate the effects of WP, CP, CHO and PLA when consumed before sleep on morning satiety and resting metabolism.

We conclude that consumption of 586 to $628 \mathrm{~kJ}$ $(140-150 \mathrm{kcal})$ of WP, CP and CHO before sleep increases morning REE in healthy, physically active young men, while that of a PLA does not. Our findings contradict the popular belief that it is advantageous to limit energy intake in the evening. In fact, protein consumption before sleep after an evening resistance exercise bout has been shown to increase muscle protein synthesis overnight in young healthy men ${ }^{(17)}$, and the results of the present study suggest that regardless of the macronutrient type, energy intake of $586-628 \mathrm{~kJ}$ $(140-150 \mathrm{kcal})$ before sleep is more beneficial than not eating. Although the aforementioned study ${ }^{(17)}$ provided a stimulus for muscle protein synthesis (resistance exercise), the present results and those of Res et $a l^{(17)}$ suggest a plausible synergistic benefit of resistance exercise and lateevening protein consumption to increase both overnight muscle protein synthesis and REE. Therefore, night-time protein and $\mathrm{CHO}$ consumption may be an effective nutritional strategy to further enhance recovery and improve resting metabolism with a minimal effect on the feelings of satiety. In addition, it is convenient to hypothesise that the improvement in morning resting metabolism may further aid in the maintenance of and/or improvement in body composition and thereby provide a competitive advantage in healthy, physically active young men. Future studies should investigate the impact of liquid energy intake $v$. solid energy intake and combinations of the macronutrients for the most optimal metabolic milieu. In addition, long-term studies of night-time feeding are warranted.

\section{Acknowledgements}

The authors thank the participants for their dedication and participation in the present study. The study was funded by the Florida State University. M. J. O. conceived and designed the study, secured funding for the project, and provided oversight for data collection, analysis and manuscript preparation. T. A. M. carried out participant recruitment and data collection and assisted with manuscript preparation. S. K. F. assisted with data collection and recruitment. A. W. K. helped with manuscript preparation. L. B. P. helped with the study design and manuscript preparation. All authors read and approved the final manuscript. None of the authors has financial or other interests concerning the outcomes of the investigation. The authors declare that they have no competing interests.

\section{References}

1. Acheson KJ, Blondel-Lubrano A, Oguey-Araymon S, et al. (2011) Protein choices targeting thermogenesis and metabolism. Am J Clin Nutr 93, 525-534.

2. Westerterp KR (2004) Diet induced thermogenesis. Nutr Metab (Lond) 1, 5.

3. Halton TL \& Hu FB (2004) The effects of high protein diets on thermogenesis, satiety and weight loss: a critical review. J Am Coll Nutr 23, 373-385.

4. Apolzan JW, Carnell NS, Mattes RD, et al. (2007) Inadequate dietary protein increases hunger and desire to eat in younger and older men. J Nutr 137, 1478-1482.

5. Poppitt SD, Proctor J, McGill AT, et al. (2011) Low-dose whey protein-enriched water beverages alter satiety in a study of overweight women. Appetite 56, 456-464.

6. Hursel R, van der Zee L \& Westerterp-Plantenga MS (2010) Effects of a breakfast yoghurt, with additional total whey protein or caseinomacropeptide-depleted alpha-lactalbumin-enriched whey protein, on diet-induced thermogenesis and appetite suppression. Br J Nutr 103, 775-780.

7. Alfenas Rde C, Bressan J \& Paiva AC (2010) Effects of protein quality on appetite and energy metabolism in normal weight subjects. Arq Bras Endocrinol Metabol 54, 45-51.

8. Latner JD \& Schwartz M (1999) The effects of a highcarbohydrate, high-protein or balanced lunch upon later food intake and hunger ratings. Appetite 33, 119-128. 
9. Soenen S \& Westerterp-Plantenga MS (2008) Proteins and satiety: implications for weight management. Curr Opin Clin Nutr Metab Care 11, 747-751.

10. Westerterp KR, Wilson SA \& Rolland V (1999) Diet induced thermogenesis measured over $24 \mathrm{~h}$ in a respiration chamber: effect of diet composition. Int J Obes Relat Metab Disord 23, 287-292.

11. Westerterp-Plantenga MS, Rolland V, Wilson SA, et al. (1999) Satiety related to $24 \mathrm{~h}$ diet-induced thermogenesis during high protein/carbohydrate vs high fat diets measured in a respiration chamber. Eur J Clin Nutr 53, 495-502.

12. Veldhorst MA, Nieuwenhuizen AG, Hochstenbach-Waelen A, et al. (2009) Comparison of the effects of a high- and normal-casein breakfast on satiety, 'satiety' hormones, plasma amino acids and subsequent energy intake. $\mathrm{Br} J$ Nutr 101, 295-303.

13. Veldhorst MA, Nieuwenhuizen AG, Hochstenbach-Waelen A, et al. (2009) Effects of complete whey-protein breakfasts versus whey without GMP-breakfasts on energy intake and satiety. Appetite 52, 388-395.

14. Veldhorst MA, Nieuwenhuizen AG, Hochstenbach-Waelen A, et al. (2009) Dose-dependent satiating effect of whey relative to casein or soy. Physiol Behav 96, 675-682.

15. Andersen LL, Tufekovic G, Zebis MK, et al. (2005) The effect of resistance training combined with timed ingestion of protein on muscle fiber size and muscle strength. Metabolism 54, 151-156.

16. Cribb PJ \& Hayes A (2006) Effects of supplement timing and resistance exercise on skeletal muscle hypertrophy. Med Sci Sports Exerc 38, 1918-1925.

17. Res PT, Groen B, Pennings B, et al. (2012) Protein ingestion before sleep improves postexercise overnight recovery. Med Sci Sports Exerc 44, 1560-1569.

18. de Castro JM (2004) The time of day of food intake influences overall intake in humans. J Nutr 134, 104-111.

19. Katayose $\mathrm{Y}$, Tasaki M, Ogata $\mathrm{H}$, et al. (2009) Metabolic rate and fuel utilization during sleep assessed by whole-body indirect calorimetry. Metabolism 58, 920-926.

20. Beelen M, Tieland M, Gijsen AP, et al. (2008) Coingestion of carbohydrate and protein hydrolysate stimulates muscle protein synthesis during exercise in young men, with no further increase during subsequent overnight recovery. J Nutr $\mathbf{1 3 8}$, 2198-2204.

21. Boirie Y, Dangin M, Gachon P, et al. (1997) Slow and fast dietary proteins differently modulate postprandial protein accretion. Proc Natl Acad Sci U S A 94, 14930-14935.

22. Groen BB, Res PT, Pennings B, et al. (2012) Intragastric protein administration stimulates overnight muscle protein synthesis in elderly men. Am J Physiol Endocrinol Metab 302, E52-E60.

23. Pennings B, Boirie Y, Senden JM, et al. (2011) Whey protein stimulates postprandial muscle protein accretion more effectively than do casein and casein hydrolysate in older men. Am J Clin Nutr 93, 997-1005.

24. Hall WL, Millward DJ, Long SJ, et al. (2003) Casein and whey exert different effects on plasma amino acid profiles, gastrointestinal hormone secretion and appetite. Br J Nutr 89, $239-248$.

25. Symons TB, Sheffield-Moore M, Wolfe RR, et al. (2009) A moderate serving of high-quality protein maximally stimulates skeletal muscle protein synthesis in young and elderly subjects. J Am Diet Assoc 109, 1582-1586.

26. Moore DR, Robinson MJ, Fry JL, et al. (2009) Ingested protein dose response of muscle and albumin protein synthesis after resistance exercise in young men. Am J Clin Nutr 89, 161-168.

27. Flint A, Raben A, Blundell JE, et al. (2000) Reproducibility, power and validity of visual analogue scales in assessment of appetite sensations in single test meal studies. Int J Obes Relat Metab Disord 24, 38-48.

28. McCrory MA, Gomez TD, Bernauer EM, et al. (1995) Evaluation of a new air displacement plethysmograph for measuring human body composition. Med Sci Sports Exerc 27, 1686-1691.

29. Karst H, Steiniger J, Noack R, et al. (1984) Diet-induced thermogenesis in man: thermic effects of single proteins, carbohydrates and fats depending on their energy amount. Ann Nutr Metab 28, 245-252.

30. Johnston CS, Day CS \& Swan PD (2002) Postprandial thermogenesis is increased $100 \%$ on a high-protein, lowfat diet versus a high-carbohydrate, low-fat diet in healthy, young women. J Am Coll Nutr 21, 55-61.

31. Nair KS, Halliday D \& Garrow JS (1983) Thermic response to isoenergetic protein, carbohydrate or fat meals in lean and obese subjects. Clin Sci (Lond) 65, 307-312.

32. Lorenzen J, Frederiksen R, Hoppe C, et al. (2012) The effect of milk proteins on appetite regulation and diet-induced thermogenesis. Eur J Clin Nutr 66, 622-627.

33. Benton MJ \& Swan PD (2007) Effect of protein ingestion on energy expenditure and substrate utilization after exercise in middle-aged women. Int J Sport Nutr Exerc Metab 17, 544-555.

34. Paddon-Jones D, Westman E, Mattes RD, et al. (2008) Protein, weight management, and satiety. Am J Clin Nutr 87, 1558S-1561S.

35. Bowen J, Noakes M, Trenerry C, et al. (2006) Energy intake, ghrelin, and cholecystokinin after different carbohydrate and protein preloads in overweight men. J Clin Endocrinol Metab 91, 1477-1483.

36. Smeets AJ, Soenen S, Luscombe-Marsh ND, et al. (2008) Energy expenditure, satiety, and plasma ghrelin, glucagonlike peptide 1 , and peptide tyrosine-tyrosine concentrations following a single high-protein lunch. J Nutr 138, 698-702.

37. Long SJ, Jeffcoat AR \& Millward DJ (2000) Effect of habitual dietary-protein intake on appetite and satiety. Appetite 35, 79-88.

38. Boirie Y, Gachon P, Corny S, et al. (1996) Acute postprandial changes in leucine metabolism as assessed with an intrinsically labeled milk protein. Am J Physiol 271, E1083-E1091.

39. Koopman R, Walrand S, Beelen M, et al. (2009) Dietary protein digestion and absorption rates and the subsequent postprandial muscle protein synthetic response do not differ between young and elderly men. J Nutr 139, 1707-1713.

40. Pennings B, Koopman R, Beelen M, et al. (2011) Exercising before protein intake allows for greater use of dietary protein-derived amino acids for de novo muscle protein synthesis in both young and elderly men. Am J Clin Nutr 93, 322-331. 